\title{
Designing an Object-based Preproduction Tool for Multiscreen TV Viewing
}

\section{J ie Li}

Centrum Wiskunde \& Informatica

Amsterdam 1098XG, NL

jie.li@cwi.nl

\section{Zhiyuan Zheng}

Centrum Wiskunde \& Informatica

Amsterdam 1098XG, NL

z.zheng@cwi.nl

\section{Britta Meixner}

Centrum Wiskunde \& Informatica

Amsterdam 1098XG, NL

britta.meixner@cwi.nl
Thomas Röggla

Centrum Wiskunde \& Informatica

Amsterdam 1098XG, NL

t.roggla@cwi.nl

Maxine Glancy

BBC Research \& Development

Salford M50 2QH, UK

maxine.glancy@bbc.co.uk

\section{Pablo Cesar}

Centrum Wiskunde \& Informatica and Delft University of Technology Amsterdam 1098XG, NL P.S.Cesar@cwi.nl

Permission to make digital or hard copies of part or all of this work for personal or classroom use is granted without fee provided that copies are not made or distributed for profit or commercial advantage and that copies bear this notice and the full citation on the first page. Copyrights for third-party components of this work must be honored. For all other

Uses, contact the Owner/Author.

(C) 2018 Copyright is held by the owner/author(s).

ACM ISBN 978-1-4503-5621-3/18/04.

https://doi.org/10.1145/3170427.3188658

\begin{abstract}
Multiscreen TV viewing refers to a spectrum of media productions that can be watched using TV and companion screens such as smartphones and tablets. In the last several years, companies are creating companion applications to enrich the TV viewing experience, but viewers are demotivated to consume them because they have to download dozens of second screen applications. This paper proposes to integrate the creation of companion screen content in a single object-based preproduction tool. It identifies, from the perspective of TV production professionals, the best paradigm and the needed features to support content authoring for multiscreen viewing experiences.
\end{abstract}

\section{Author Keywords}

Object-based broadcasting; multiscreen viewing; preproduction; graphical interface design.

\section{ACM Classification Keywords}

H.5.2 [Information Interfaces and Presentation]: User Interfaces---evaluation/methodology and graphical user interfaces (GUI).

\section{Introduction}

Lately, the prevalence of smart companion devices (i.e., tablets and smartphones) have dramatically changed the way TV is consumed. It is increasingly common to see people watching TV, while interacting with their companion devices [10]. Research about 


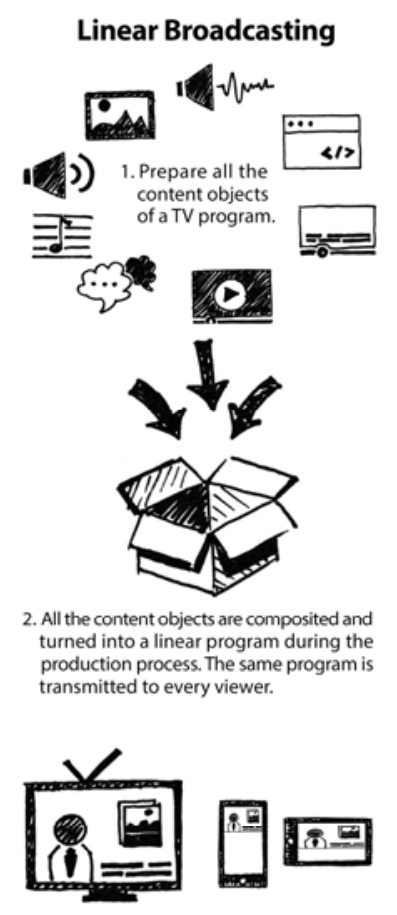

3. The same program is displayed on all kinds of devices, which can neither be tailored
to the viewers' contexts nor allow viewers to interact meaningfully.

Figure 1: Traditional linear broadcasting multiscreen viewing experiences is multi-faceted. Some of the work focuses on understanding the viewers' experience $[2,11]$, while other work focuses on the development process of the companion applications [9, $11,13]$ that synchronize with the TV program. Even though much effort is invested on companion apps, few of them have successfully reached the mass audiences [3]. One reason that hinders its popularization is that there is no standard process for producing companion screen content. Companies are creating their own companion apps in an ad-hoc manner, which becomes impractical for viewers since they are forced to install and switch between dozens of apps. Geerts et al. [6] suggested to provide a single platform with which viewers could follow all the companion screen shows of a broadcaster.

Rather than outsourcing to a third party (e.g., technology companies or different teams within the TV channel) to develop companion applications, this workin-progress paper proposes to integrate the creation of companion screen content in the preproduction process. Producers will be thus expected to efficiently develop and control various versions and formats for different screens. To do so, four initial concepts of an object-based preproduction tool were designed according to the functional and user requirements collected in a previous study [8]. Ten professionals in the TV production industry were invited to evaluate these concepts. The research question was to identify the best paradigm and needed features to support authoring multiscreen experiences.

\section{Related Work: Object-based Production}

What is an object-based media production? Here, "object" refers to different interactive media units that are used to make a TV program. The object-based approach involves breaking down a program into separate content objects, typically including graphics, audio, video, background music, dialogues, subtitles, sound/visual effects etc., and describing how they can be rearranged. Following this approach, a program can be adapted to fulfill the needs of different individual viewers [7]. As a summary, Figure 1 and 2 compares the traditional linear TV program broadcasting and the object-based broadcasting.

Some recent studies have explored object-based production in different use cases. For instance, a cooking show application CAKE that breaks the show into many shots and generates a step-by-step cooking plan to adapt to the viewer's pace [4]. Squeezebox enables to rapidly re-edit the durations of the content by automatically analyzing and segmenting the footage into individual shots [1]. Puentes et al. [12] developed a flexible visual authoring tool called WYSIWYG (What you see is what you get). By dragging and dropping static or dynamic "components (e.g., texts, images, videos, audio, fonts etc.)" into "containers (e.g., defined regions on the screens)", developers and designers become time-and-cost-efficient in creating interactive TV applications. However, most of the object-based applications are focusing on a specific element of the media production, like CAKE and Squeezebox. WYSIWYG focuses on the spatial features (e.g., visual representations and interactive mechanisms), but does not provide any temporal features (e.g., a timeline).

The object-based preproduction tool proposed in this paper has both spatial and temporal features. It produces programs by configuring and assembling a collection of re-usable interactive media units (DMApp components) that can deliver coherent viewing experiences for multiple screens. The set of DMApp components are actually a set of content objects, which can also be configured to have some interactive and novel functions, such as "like" widget (for expressing "like" preference), real-time video chat or text chat, which can stimulate viewers' engagement. The DMApp 


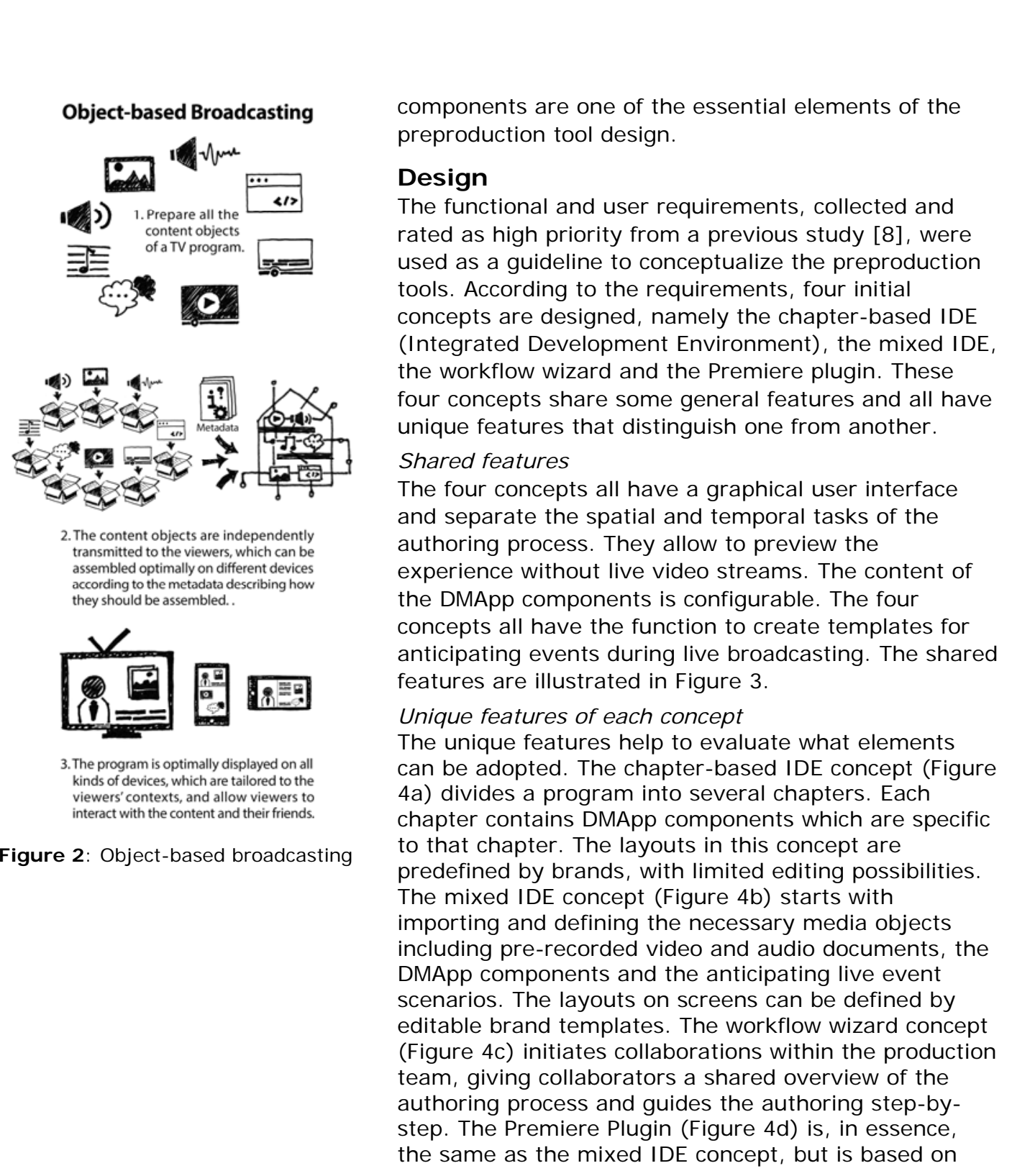

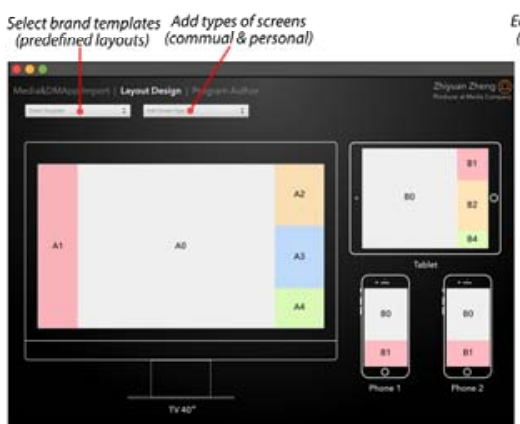

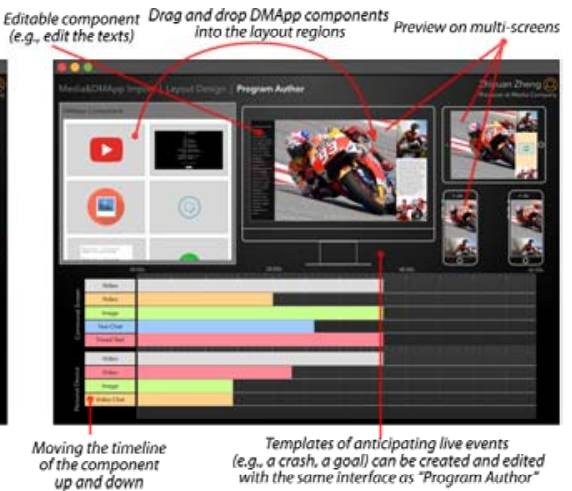

Figure 3: The "Layout Design" interface (left) and the "Program Author"

interface (right) are shared by the four concepts. The characteristics in common are pointed out with red lines and explanatory texts.
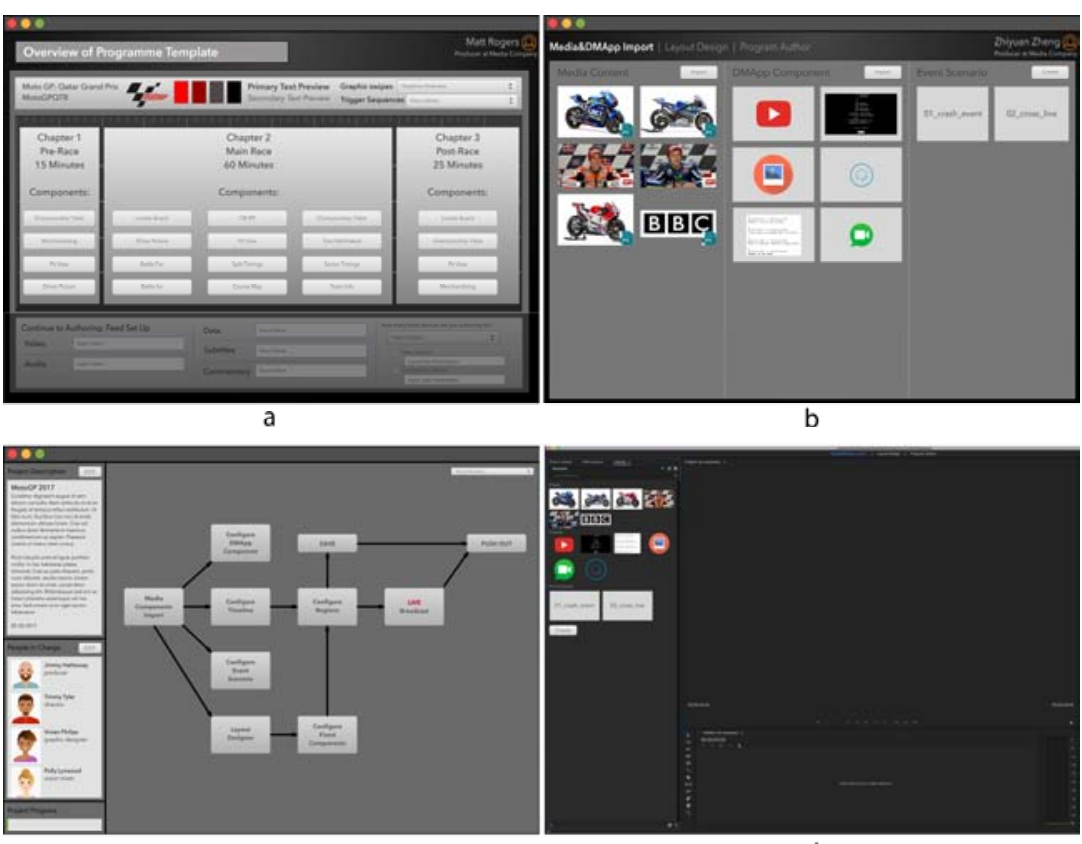

Figure 4: Four unique concepts: (a) Chapter-based IDE, (b) Mixed IDE, (c) Workflow wizard, and (d) Premiere plugin. 


\section{Background}

\begin{tabular}{|c|c|}
\hline P1 & $\begin{array}{l}\text { Head of interactive TV research at } \\
\text { British Telecom, focusing on next } \\
\text { generation multiscreen and } \\
\text { immersive TV application. }\end{array}$ \\
\hline P2 & $\begin{array}{l}\text { Director/producer of screen } \\
\text { productions at Illuminations } \\
\text { Media, experienced in } \\
\text { broadcasting and film. }\end{array}$ \\
\hline P3 & $\begin{array}{l}\text { Film maker and content producer } \\
\text { at BBC, experienced in the } \\
\text { provision of intergenerational } \\
\text { content, the use of haptic } \\
\text { feedback devices for accessibility } \\
\text { and editorial purposes and } \\
\text { development of ambient media } \\
\text { prototypes. }\end{array}$ \\
\hline P4 & $\begin{array}{l}\text { Senior development producer for } \\
360 \text { videos, virtual reality, } \\
\text { immersive experiences at BBC. }\end{array}$ \\
\hline P5 & $\begin{array}{l}\text { Senior technology transfer } \\
\text { manager at BBC, focusing on The } \\
\text { New Broadcasting System based } \\
\text { on IP production as well as general } \\
\text { production workflows. }\end{array}$ \\
\hline P6 & $\begin{array}{l}\text { Lead research and development } \\
\text { engineer at BBC, leading the } \\
\text { Object-based media (OBM) work } \\
\text { stream within group of Future } \\
\text { Experience Technology, building } \\
\text { tools that can be used to create } \\
\text { OBM experiences, and researching } \\
\text { whether OBM can bring efficiencies } \\
\text { to traditional program making; }\end{array}$ \\
\hline P7 & $\begin{array}{l}\text { Executive director, new workflow } \\
\text { research director at BBC, } \\
\text { experienced in developing } \\
\text { innovative tools for critical creative } \\
\text { tasks, including the production of } \\
\text { subtitles and shot planning for } \\
\text { multi-camera TV direction. }\end{array}$ \\
\hline P8 & $\begin{array}{l}\text { New workflow researcher at BBC, } \\
\text { focusing on investigating, } \\
\text { informing and evaluating media } \\
\text { experiences of the now and } \\
\text { longer-term future. }\end{array}$ \\
\hline P9 & $\begin{array}{l}\text { Creative director for production } \\
\text { systems at BBC, experienced in } \\
\text { user experience design and design } \\
\text { of editorial systems. }\end{array}$ \\
\hline P10 & $\begin{array}{l}\text { Research and development } \\
\text { engineer at } B B C \text {, focusing on new } \\
\text { types of synchronised companion } \\
\text { screen experiences for connected } \\
\text { homes. }\end{array}$ \\
\hline
\end{tabular}

invited for the evaluation interviews the interface of Adobe Premiere. Since it is assumed that most program authors are expert users of Adobe Premiere, the idea is to increase their feeling of familiarity and ease of use.

\section{Evaluation: I nterviews}

The goal of the interviews was to collect feedback from professionals about the four concepts, which lead to a guideline for the final design. Eight semi-structured interviews [13] were conducted in March 2017 at the BBC usability lab. All interviews were one-to-one conversations except one, which was conducted with three professionals (P6, P7 \& P8), due to their limited time availability

Interviewees

Ten broadcasting professionals (P1-P10) with diverse backgrounds were invited to evaluate the concepts, including (creative) director, R\&D engineer, film maker, technology manager etc. Even most of them are now at the senior executive level, they are still actively leading and participating in media productions (see Table 1).

Procedure

The wireframes of the four concepts were printed on A4 papers. One interviewer facilitated the interviews. The order of the four concepts was randomized for each interview. Every interview had three steps and took about one hour.

- Step 1: Introduction (5 minutes): The facilitator introduced the context and the four concepts.

- Step 2: Evaluation using thinking-aloud method (45 minutes) [5].

- Step 3: Follow-up interview questions (10 minutes): Clarify the preferences and recommendations.

Data collection and analysis

The interviews were video and audio recorded. The audio records were transcribed into text. The video records were used to clarify ideas during the

transcription process. A group of three researchers selected the relevant paragraphs from the transcripts according to the goals and gave the selected texts a brief description. The coded texts were then sorted into three main categories, namely strengths and weaknesses of each concept, order of preferences and improvement suggestions. These categories of information indicate a direction for redesigning the production tool.

\section{Results}

This section presents a concise version of the results of the interviews.

Strengths and weaknesses of each concept

The mixed IDE concept received the most compliments for its simplified way of defining layouts and positioning components. The workflow wizard concept was appreciated by its ability to initiate collaborations, but also critiqued the most due to the expected interference between multiple collaborators and its inability to return to previous steps. The chapter-base IDE concept was complimented for specifying "chapters" for a program, but the chapters were considered by professionals as too simplified compared to the actual production workflow. The Premiere plugin concept was regarded as "easy to learn" due to the familiarity of the interface. However, they pointed out that Premiere may not be suitable for managing production.

Preferences of the four concepts

The professionals were requested to order the four concepts according to their preferences. P1 and P10 did not indicate any preferences. Table 2 exhibits the results. The Mixed IDE concept is preferred by the most professionals.

Suggestions

The professionals also mentioned some aspects that are important for the multiscreen preproduction tool design. 


\begin{tabular}{|c|c|c|c|c|}
\hline & C1 & C2 & C3 & C4 \\
\hline P1 & \multirow{2}{*}{\multicolumn{4}{|c|}{ No preferences }} \\
\hline P2 & & & & A \\
\hline P3 & \multicolumn{3}{|l|}{$\mathrm{B}$} & A \\
\hline P4 & \multirow{2}{*}{\multicolumn{2}{|c|}{$\begin{array}{cc}\text { B } & \text { A } \\
\text { No preferences }\end{array}$}} & & \\
\hline P5 & & & & \\
\hline P6 & \multirow{2}{*}{\multicolumn{2}{|c|}{$B$}} & & \\
\hline P7 & & & \multicolumn{2}{|l|}{$B$} \\
\hline P8 & & A & & B \\
\hline P9 & $\mathrm{B}$ & A & & \\
\hline P10 & No p & ences & & \\
\hline Total & $A+4 B$ & $4 A+B$ & B & $2 A+B$ \\
\hline
\end{tabular}

Table 2: The preferences of the four Table 2: The preferences of the four
concepts by the ten professionals, P1 \& P10 indicated no preferences toward the four concepts ( $A=$ =First preference; $\mathrm{B}=$ Second preference; $\mathrm{C} 1=$ Chapterbased IDE; $C 2=$ Mixed IDE; C3=Workflow Wizard; $C 4=$ Premiere Plugin).

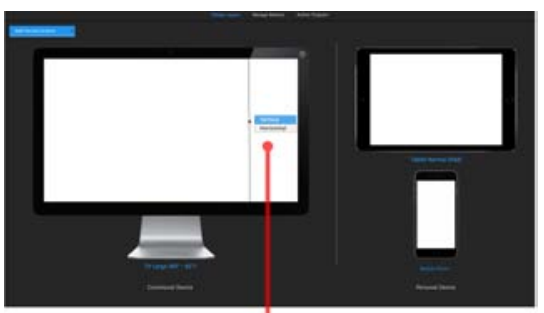

Click on the screen and
select how to divide it

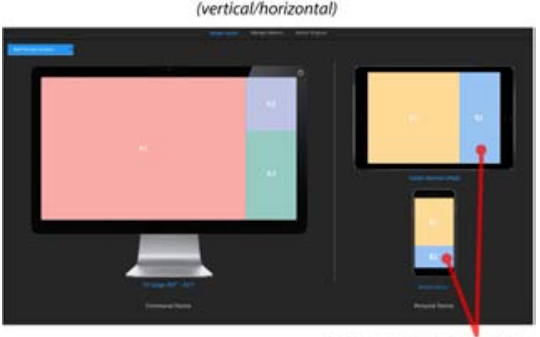

Regions with the same color
will display the same content

Figure 5: The advanced mode of layout design: Click on the screen to divide it vertically or horizontally (above); Label the regions with names and colors (below). Regions with the same color will display the same content.
During the preproduction phase of a live program, timeline is not relevant, because the length of live events is unpredictable. Live broadcasting is event driven and sequence-based (P1, P3, P5, P6, P9, P10). Instead of the timeline, P2 suggested that an eventline is helpful for rapidly rearranging contents during live broadcasting.

Hierarchical organizations of contents are advised by a few professionals. Each piece of content should be encoded specifically for accurately retrieving later (P4 \& P5). P9 pointed out that DMApp components should be organized according to the frequency of usage. P9 also suggests a hierarchical organization of the chapters to form a tree-like system, which provides flexibility to edit contents in chapters.

P4 and P9 pointed out that layouts may vary in different chapters, so layout design should allow certain flexibility. The professionals proposed two modes of layout design. One is the advanced mode, where they need arrange content objects on a region-less screen. Another is the normal mode, where templates are provided.

\section{Final Design}

Based on the results, the selected mixed IDE concept is re-designed. Figure 5 and 6 show featured screen shots of the re-designed wireframes. Figure 5 illustrates the layout design mechanism in the advanced mode. Figure 6 depicts the eventline and event templates creation. Figure 6a shows the way to create a master layout, for example, a master layout of the "main logo". Figure 3d exhibits a three-level hierarchical overview of the program. From top to bottom, these levels are the program level, the chapter level and the experience level. Once created, the master layout can be applied at the program level. Then, the same master layout will be automatically added at the chapter level and the experience level. The master layout largely reduces repetitive work. Figure $6 \mathrm{c}$ and $6 \mathrm{~d}$ are similar, both including previews on multiple screens, eventline and a library of DMApp components. Clicking at one of the documents at the experience level will direct to the interface shown in Figure $6 c$, where an experience can be created, previewed and edited. The interface shown in Figure $6 \mathrm{~d}$ has the same function, but for creating, previewing and editing live events, such as a crash at a motorcycle race or a goal in a football match.

\section{Conclusion and Future Work}

This paper presents the design and evaluation of an object-based preproduction tool. The professionals found that the paradigm that provides a hierarchical overview of the program chapters can best

accommodate to the authoring for multiscreens. Features such as two modes of screen layout design, re-usable DMApp components, master layout, and templates for live events are considered important. We also realized that the preproduction of live broadcasting can be distinct from recorded broadcasting due to unpredictable events. In the future, an observational field study is planned at an Outside Broadcasting tuck (OB truck) for a sport show, aiming at understanding the current workflow of live production, and how the tool can be integrated into that workflow and better help the preproduction as well as live production. The final design of the preproduction tool is ongoing work. A validation study is planned by the end of J anuary,

2018. The goal of the validation study is to see whether the proposed object-based workflow is appropriate, and how the tool can fit into the existing workflow and who will be the potential users.

\section{Acknowledgement}

This work is supported by European Union's Horizon 2020 research and innovation program under grant agreement No 687655, project 2-IMMERSE. 


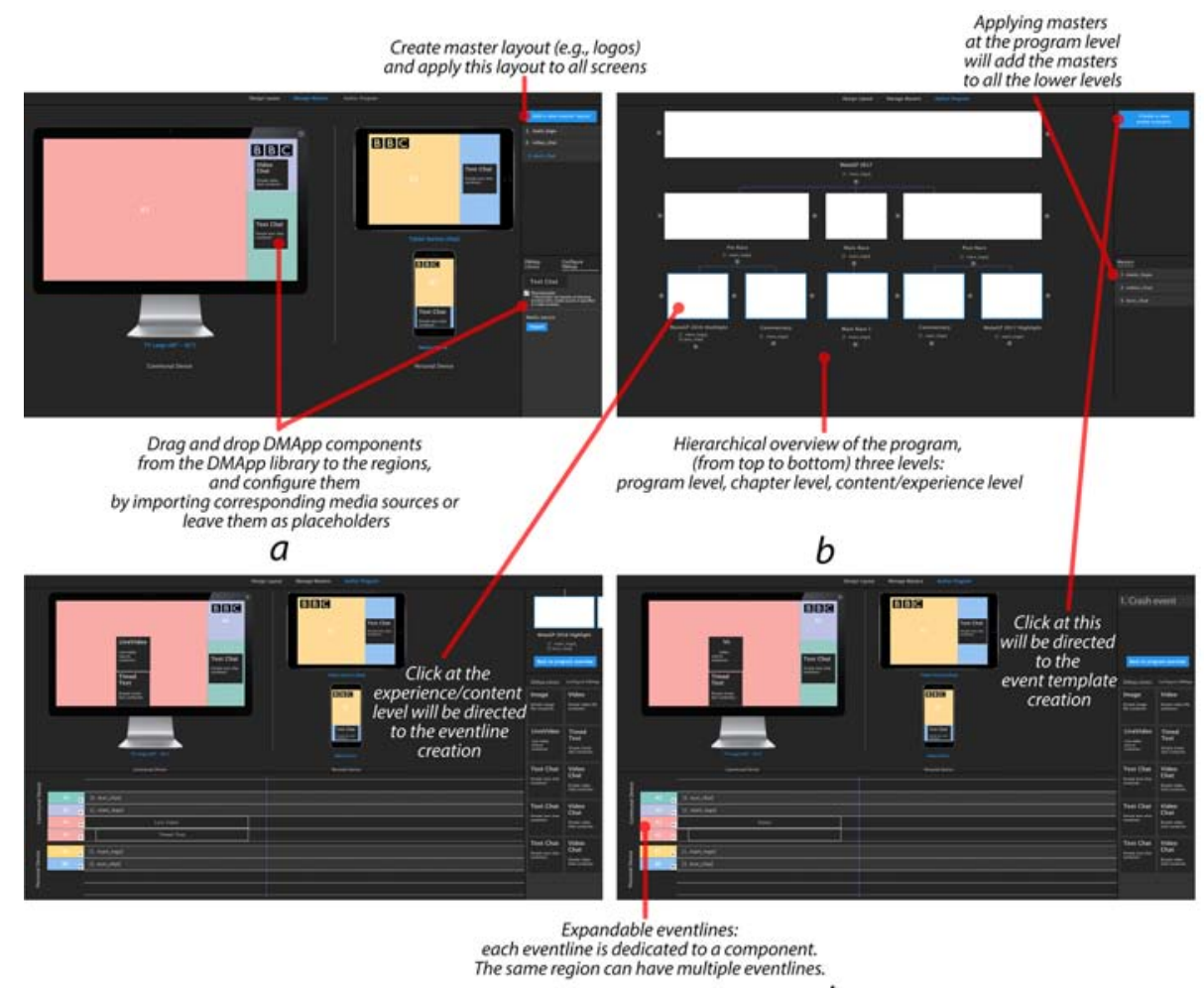

Figure 6: The eventline and event templates creation: (a) Create master layout, (b) Hierarchical overview of the program, (c) Create and edit content at the experience level, and (d) Create and edit content for live events.

\section{References}

1. BBC Research \& Development. 2015. Squeezebox: A production tool that can edit for you. Retrieved December 5, 2017 from

http://www. bbc.co.uk/rd/projects/squeezebox

2. Frank R. Bentley. 2017. Understanding Secondary Content Practices for Television Viewing. In Proceedings of TVX '17, 123-128. ACM.

3. Pablo Cesar. 2015. From secondary screens to socially-aware and immersive experiences (invited talk). In María José Abásolo, Francisco J. Perales and Antoni Bibiloni (Eds.), Applications and Usability of Interactive TV, p. VII-VIII.

4. Jasmine Cox, Rhianne J ones et al. 2017. ObjectBased Production: A Personalised Interactive Cooking Application. In Adjunct Publication of TVX '17, 79-80. ACM.

5. K. Anders Ericsson and Herbert A. Simon. 1980. Verbal reports as data. Psychological Review, 87 (3), 215-251.

6. David Geerts, Rinze Leenheer et al. 2014. In front of and behind the second screen: Viewer and producer perspectives on a companion app. In Proceedings of TVX '14, 95-102. ACM.

7. Ian Kegel, James Walker et al. 2017. 2-I MMERSE: A platform for orchestrated multiscreen entertainment. In Adjunct Publication of TVX '17, 71-72. ACM.

8. Britta Meixner, Maxine Glancy et al. 2017. Multiscreen director: A new role in the TV production workflow?. In Adjunct Publication of TVX '17, 5762. ACM.

9. Janet Murray, Sergio Goldenberg et al. 2012 Story-map: iPad companion for long form TV narratives. In Proceedings EurolTV '12, 223-226. ACM.

10. Abhishek Nandakumar and Janet Murray. 2014 Companion apps for long arc TV series: supporting new viewers in complex storyworlds with tightly synchronized context-sensitive annotations. In Proceedings TVX '14, 3-10. ACM.

11. Timothy Neate, Matt Jones, and Michael Evans. 2015. Mediating Attention for Second Screen Companion Content. In Proceedings of $\mathrm{CHI}$ '15, 3103-3106. ACM.

12. Carlos A. N. Puentes and José T. H. Peñaloza. 2017. HEd: A Flexible HbbTV WYSIWYG Visual Authoring Tool. In Adjunct Publication TVX '17, 1520. ACM.

13. Marina Remington and P. Tyer. 1979. The social functioning schedule: A brief semi-structured interview. Social Psychiatry, 14, 151-157.

14. Pedro Silva, Yasmin Amer et al. 2015. A Game of Thrones Companion: Orienting Viewers to Complex Storyworlds via Synchronized Visualizations. In Proceedings of TVX '15, 167-172. ACM. 